\title{
Oral contraceptive use, the menstrual cycle, and the need for sleep
}

\author{
ROBERT A. HICKS and ANN M. CAVANAUGH \\ San Jose State University, San Jose, California 95192
}

\begin{abstract}
A group of 49 university students, including 9 contraceptive pill users and 40 nonusers, kept daily sleep logs and menstrual calendars for at least two complete menstrual cycles. On the basis of these data, the menstrual cycle of each woman was divided into four phases, and a mean sleep duration was computed for each phase. A significant Group by Phase interaction was computed. This interaction resulted from the fact that the peak need for sleep occurred at different menstrual cycle phases for the contraceptive users and nonusers and that the users showed a significantly greater need for sleep during three of the four menstrual cycle phases.
\end{abstract}

We are reporting evidence that links fluctuations in sleep duration to the interaction of menstrual cycle phase and oral contraceptive use. In part, our interest in this combination of variables was the result of Ruble's (1977) demonstration that the several studies that had attempted to relate wakeful affective state(s) to the menstrual cycle were seriously confounded. That is, Ruble demonstrated that the use of periodic self-reports of affective state (a consistent design feature of these studies) was biased by women's attitudes regarding the way that they were "supposed to feel" during the various phases of their menstrual cycles. We felt that daily recordings of sleep duration could provide indirect insight into fluctuations of affective state that were not confounded by the factor identified in Ruble's study. In this regard, it is well documented that stressful events influence sleep and dreams (see Schultz \& Koulack, 1980, for a review). Further, Hartmann and Brewer (1976) have demonstrated that sleep duration changes reliably as a function of exposure to stressful events. That is, they found that when things were "going well" people reported needing less sleep and, conversely, during times of stress they reported needing more sleep. Thus, self-reported sleep duration could be viewed as a reflection of changes in affective state.

Typically, (e.g., see Schultz \& Koulack, 1980) oral contraceptive users have been excluded from consideration in studies designed to measure relationships between the menstrual cycle and parameter of sleep and/or dreaming. We felt that this variable should be manipulated in this type of research since there is limited evidence that suggests that oral contraceptive use may effect sleep state patterns (Ho, 1972-1973) and dreaming (Sheldrake \& Cormack, 1976). Therefore, the general purpose of this study was to assess fluctuations in sleep duration of groups of oral contraceptive users and nonusers as a function of menstrual cycle phases.

Requests for reprints should be addressed to Robert A. Hicks, Department of Psychology, San Jose State University, San Jose, California 95192.

\section{METHOD}

\section{Subjects}

The subjects were 49 female undergraduates (mean age $=$ 20.5 years) who had volunteered to keep the daily records required for this research. Forty of these women were not using oral contraceptives $(\mathrm{OCN})$ and nine were using oral contraceptives (OCU) during the term of this study.

\section{Procedure}

The subjects were asked to keep sleep logs on which they recorded, each day, the approximate times of sleep onset and awakening for both nocturnal sleep and napping. From these data, we computed total sleep time for each subject for each day. In addition, each subject was asked to keep a menstrual calendar and to respond each day to a series of questions that concerned the use of drugs and medications that could affect subsequent sleep patterns. Every subject contributed daily data for at least two complete menstrual cycles, and most, for three complete menstrual cycles.

Then, on the basis of the menstrual calendar data, the menstrual cycles of each subject were organized into four equal phases (these are listed in Table 1), and then we computed a mean sleep duration for each of these menstrual phases for each subject, using all the relevant daily data for that subject. Here, it should be noted that we excluded any sleep duration data that might be biased by the use of a sleep-altering drug.

\section{RESULTS AND DISCUSSION}

The mean sleep durations for each group for the four menstrual phases are given in Table 1 . The data summarized in Table 1 were first analyzed using a 2 (groups) by 4 (phases) analysis of variance with repeated measures in the second factor. The main effects for groups $[F(1,47)=1.73]$ and phases $[F(3,141)=2.05]$ were not significant. However, the Groups by Phases interaction was significant. The reason for this significant interaction is apparent in the pattern of means given in Table 1. The need for sleep peaked at different phases of the menstrual cycle for the OCU and OCN groups. Further, for three of the four phases of the cycle, the OCU group showed significantly longer sleep durations than the OCN group (for menses, $t=1.85, p<.10$; for preovulation, $\mathrm{t}=2.54, \mathrm{p}<.02$; for ovulation, $\mathrm{t}=2.08$, $\mathrm{p}<.05$; and for postovulation, $\mathrm{t}=.84$, n.s.). 
Table 1

Mean Hours of Sleep for Each Group for Each Menstrual Cycle Phase

\begin{tabular}{|c|c|c|c|c|c|c|c|c|}
\hline \multirow[b]{3}{*}{ Group } & \multicolumn{8}{|c|}{ Menstrual Cycle Phase } \\
\hline & \multicolumn{2}{|c|}{ Menses } & \multicolumn{2}{|c|}{ Preovulation } & \multicolumn{2}{|c|}{ Ovulation } & \multicolumn{2}{|c|}{$\begin{array}{c}\text { Post- } \\
\text { ovulation }\end{array}$} \\
\hline & Mean & SD & Mean & SD & Mean & SD & Mean & SD \\
\hline $\begin{array}{l}\text { OCU } \\
\text { OCN }\end{array}$ & $\begin{array}{l}8.17 \\
7.80\end{array}$ & $\begin{array}{l}.47 \\
.80\end{array}$ & $\begin{array}{l}8.37 \\
7.71\end{array}$ & $\begin{array}{l}.72 \\
.71\end{array}$ & $\begin{array}{l}8.10 \\
7.56\end{array}$ & $\begin{array}{l}.67 \\
.91\end{array}$ & $\begin{array}{l}7.50 \\
7.77\end{array}$ & $\begin{array}{l}.84 \\
.81\end{array}$ \\
\hline
\end{tabular}

Thus, if one can argue that sleep need is directly related to the stressfulness of wakeful events, then it seems reasonable to suggest that the phases of the menstrual cycle are differentially stressful for oral contraceptive users and nonusers. While the validity of this finding remains to be determined, it should be instructive to those who are interested in sleep research with adult women.

\section{REFERENCES}

Hartmann, E., \& Brewer, V. When is more or less sleep required? A study of variable sleepers. Comprehensive Psychiatry, 1976, 17, 275-284.

Ho, M. A. Sex hormones and the sleep of women. Dissertation Abstracts International, 1972-1973, 33, 1305-B.

Ruble, D. N. Premenstrual symptoms: A reinterpretation. Science, 1977, 197, 291-292.

Schultz, K. J., \& Koulack, D. Dream affect and the menstrual cycle. Journal of Nervous and Mental Disease, 1980, 168, 436-438.

Sheldrake, P., \& Cormack, M. Dream recall and the contraceptive pill. Journal of Nervous and Mental Disease, 1976, $163,59-60$.

(Received for publication January 31, 1982.) 